\title{
Penerapan QRCode Sebagai Media Pelayanan Untuk Absensi Pada Website Berbasis PHP Native
}

\section{Application of QRCode as Media Services for Attendance on the Website Based Php Natively}

\author{
Qurotul Aini ${ }^{1}$, Untung Rahardja ${ }^{2}$, Anggy Fatillah ${ }^{3}$ \\ Dosen Sistem Informasi STMIK Raharja ${ }^{1}$, Dosen Sistem Informasi STMIK Raharja ${ }^{2}$, \\ Mahasiswa STMIK Raharja Jurusan Sistem Komputer ${ }^{3}$ \\ Aini@raharja.info ${ }^{1}$, untung@raharja.info ${ }^{2}$, Anggy@raharja.info ${ }^{3}$
}

\begin{abstract}
Abstrak
Pada perguruan tinggi absensi asisten lab adalah suatu hal yang sangat penting untuk menunjukan kehadiran seseorang asisten lab. Proses absensi asisten lab yang berjalan saat ini masih secara manual yaitu menggunakan kertas sehingga cara ini tidak efektif karena dapat di manipulasi. Selain itu rekapan berkas kertas absensi akan menumpuk setiap harinya dan sulit untuk merekap sehingga tidak tertata rapih. penulis melakukan metode penelitian, pengumpulan data dan perumusan masalah yang terjadi pada proses absensi. Hasil akhir dari penelitian ini adalah menggunakan sistem baru yang bernama Pensil (Penilaian Asisten Lab) yang dimana saat ini masih dalam tahap proses pembuatan. Dalam sistem ini menerapkan absensi menggunakan qrcode, proses absensi yang berjalan jika menggunakan Pensil hanya tinggal create generate qrcode pada sebuah website pensil.raharja.ac.id lalu tinggal scan qrcode pada device yang telah di sediakan. Dengan adanya sebuah sistem baru ini diharapkan absensi asisten lab menjadi efektif.
\end{abstract}

Kata Kunci-Absensi, Asisten Lab, Qrcode

\begin{abstract}
On College attendance assistant lab is a thing that is very important to indicate the presence of a lab assistant of someone. The process of running a lab assistant attendance still manually namely use paper so this method is not effective because it can be manipulated. In addition the paper file rekapan absences will pile up each day and it is difficult to direkap so it is not well presentable. the author does research methods, data collection and the formulation of problems that occur in the process of attendance. The end result of this research is to use the new system named Pencil (assessment of Lab Assistant) which is currently still in the stages of the manufacturing process. In this system implemented using qrcode attendance, attendance process running if you use Pencil only create generate qrcode on a website pensil.raharja.ac.id and then live scan qrcode on device that has been provided. The existence of a new system is expected to be an effective lab assistant attendance.
\end{abstract}

Keyword-Attendance, Assistant Lab, Qrcode

\section{PENDAHULUAN}

Absensi memiliki peran penting dalam kehidupan sehari-hari terutama di lingkungan sekolah, universitas, pabrik, perkantoran, rumah sakit dan tempat lain yang membutuhkan Absensi. Di dalam kegiatan perkuliahan pastinya menjadi sangat penting bagi mahasiswa yang mengikuti pembelajaran dan pertanda mengikuti kegiatan perkuliahan dan banyak beberapa device untuk absensi. 
Pada Perguruan Tinggi Raharja absensi asisten lab masih menginput NIM dan password pada website RME yang masih localhost dan bisa terjadi manipulasi untuk menitip absen kemudian penanggung jawab asisten lab untuk memberikan penilaian dan merekap absensi asisten lab masih menginput satu persatu nim dari asisten lab kepada website RME.

Asisten lab Perguruan Tinggi Raharja dan penanggung jawab asisten lab Perguruan Tinggi Raharja membutuhkan website online dan untuk login ke website nya menggunakan single sign on magic key Rinfo setelah login langsung create Qrcode dan scan kepada device yang tersedia di lab ilearning agar absensi tidak terjadi manipulasi dan agar penanggung jawab asisten lab bisa memberikan penilaian kepada asisten lab karena di website online sudah ada viewboard.

Tujuan penelitian ini untuk meningkatkan absensi asisten lab secara online dan memudahkan penanggung jawab asisten lab untuk merekap kehadiran absen asisten lab.

Penelitian yang dilakukan oleh Imron [1] kehadiran siswa di sekolah (school attendance) adalah kehadiran dan keikutsertaan siswa secara fisik dan mental terhadap aktivitas sekolah. Sedangkan ketidahadiran adalah ketiadaan partisipasi secara fisik siswa terhadap kegiatan kegiatan sekolah. Pada jam - jam efektif sekolah, siswa memang harus berada di sekolah. Kalau tidak ada di sekolah, seyogyanya dapat memberikan keterangan serta diketahui orang tua atau walinya.

Penelitian yang dilakukan Siti Ria Zuliana [2] dalam penyampaian informasi saat ini dibutuhkan sistem yang cepat dan mudah untuk diakses secara online anywhere and anytime yang diberikan harus selalu up to date. Perkembangan internet berkembang begitu pesat dan terus berinovasi dan menciptakan terobosan yang baru.

Penelitian yang dilakukan Erna Simmona [3] Absensi adalah suatu pendataan kehadiran, bagian dari pelaporan aktifitas suatu institusi, atau komponen institusi itu sendiri yang berisi data-data kehadiran yang disusun dan diatur sedemikian rupa sehingga mudah untuk dicari dan dipergunakan apabila sewaktu-waktu diperlukan oleh pihak yang berkepentingan. Kita mengenal beberapa jenis absensi. Yang membedakan jenis-jenis absensi tersebut adalah cara penggunaannya, dan tingkat daya gunanya Secara umum jenis-jenis absensi dapat di kelompokkan menjadi dua, yaitu a) Absensi manual, adalah cara pengentrian kehadiran dengan cara menggunakan pena (tanda tangan); dan b) Absensi non manual (dengan menggunakan alat), adalah suatu cara pengentrian kehadiran dengan menggunakan system terkomputerisasi, bisa menggunakan kartu dengan barcode, finger print ataupun dengan mengentrikan nip dan sebagainya.

Penelitian yang di lakukan oleh Anwar [4] penilaian adalah proses sistematik meliputi pengumpulan informasi (angka atau deskripsi verbal), analisis, dan interpretasi untuk mengambil keputusan.

Penelitian yang di lakukan oleh Fitria Nursetianingsih [5] Absensi merupakan salah satu bentuk kedisiplinan pegawai yang juga membantu meningkatkan motivasi di setiap aktivitas perusahaan. Profesionalisme adalah komitmen para anggota suatu profesi untuk meningkatkan kemampuannya secara terus menerus. Dan dalam hal ini absensi merupakan salah satu tolok ukur suatu profesionalisme pegawai. Seseorang yang memiliki jiwa profesionalisme senantiasa mendorong dirinya untuk mewujudkan kerja yang profesional juga. Dalam segi kedisiplinan, data absensi setiap pegawai dapat diolah dan ditampilkan pada dashboard yang efektif agar penyajian informasi memberikan kejelasan pada penggunanya.

Penelitian yang dilakukan oleh Santika [6] Dengan metode sistem berbasis online, sistem pelayanan dukungan tersebut akan sangat mudah untuk didapatkan. Adapun ROOSTER merupakan sebuah aplikasi sistem pelayanan dukungan berbasis online yang sangat praktis. Dalam artikel ini di jelaskan mengenai masalah masalah yang timbul serta pemecahan masalah yang diteliti.

Penelitian yang dilakukan oleh Reski Martha Utami [7] Sistem Absensi online merupakan kemajuan teknologi, khususnya teknologi informasi, dimana informasi tersebut tentu saja tidak dapat maksimal di serap dengan hanya mengandalkan perangkat-perangkat yang 
masih kuno dan serba manual. Maka dari itu kegunaan komputer sangatlah penting dalam memberikan solusi dan merupakan alat bantu yang cukup baik dalam memperbaiki sistem yang belum optimal.

Penelitian yang telah dilakukan oleh Dhita Rukmianti [8] diusulkan untuk memperbaiki kekurangan yang ada pada sistem yang berjalan dimana sistem belum mampu menyediakan informasi yang dibutuhkan dengan cepat karena masih menggunakan system manual. Proses absensi yang diusulkan menggunakan system terpusat sehingga hasil dari proses system informasi dapat sesuai dengan yang diharapkan, dan dapat lebih meningkatkan manajemen dalam kedisiplinan pegawai berdasarkan data absensinya.

Dari definisi tersebut dapat disimpulkan absensi merupakan suatu hal yang sangat penting karena memiliki peran dalam kehadiran seseorang mahasiswa, walaupun absensi ada yang masih manual, oleh karena itu diperlukan pengambilan keputusan yang tepat agar dapat memperhitungkan proses absensi secara efektif.

Di Perguruan Tinggi Raharja saat asisten lab mengikuti kegiatan Tri dharma proses absensinya dengan cara input NIM dan password kepada komputer yang di sediakan, lalu penanggung jawab asisten lab bertugas untuk merekap absensi asisten lab dengan menginput nama atau NIM asisten lab satu persatu.

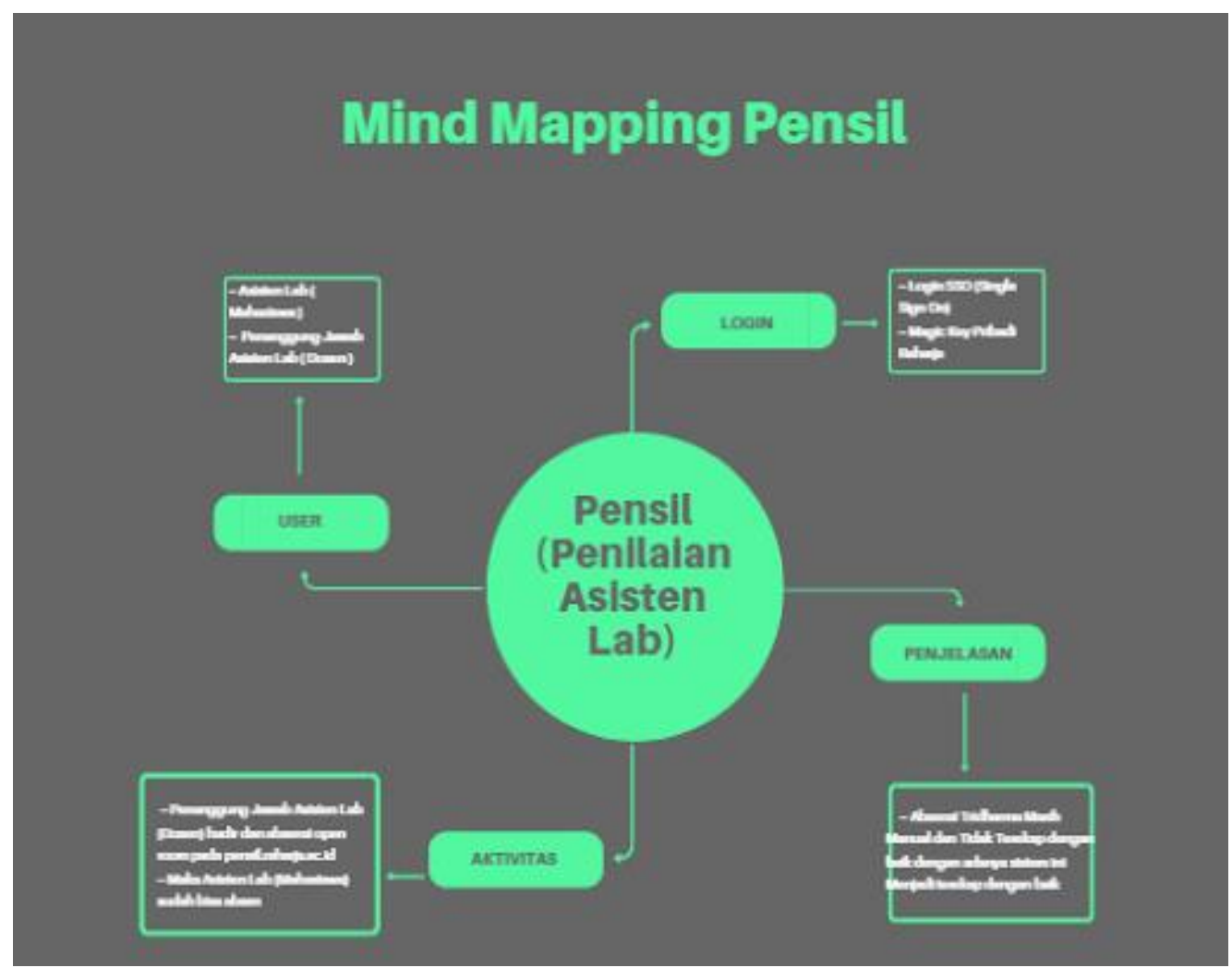

Gambar 1. Mind Mapping Pensil

Gambar di atas merupakan tampilan Mind Mapping atau disebut juga gambar tentang pemetaan menjelaskan deskripsi tentang Pensil (Penilaian Asisten Lab) yaitu:

a. User yang terdapat dalam Pensil memiliki 2 user yaitu Asisten Lab (Mahasiswa) dan Penanggung Jawab Lab (Dosen).

b. Login SSO (Single Sign On) dan Menggunakan Magics Key Raharja yaitu Rinfo. Aktifitas Penanggung Jawab Lab (Dosen) hadir dan absen Open Room pada sistem pensil.raharja.ac.id Maka Asisten Lab (Mahasiswa) sudah bisa Absensi dengan Scan Qrcode pada pensil.raharja.ac.id. 
c. Aktivitas yang ada di dalam sistem Pensil adalah Penanggung Jawab Asisten Lab (Dosen) hadir dan absensi open room pada pensil.raharja.ac.id maka Asisten Lab (Mahasiswa) sudah bisa absen.

d. Penjelasan ini menjelaskan Absensi Tri Dharma Asisten Lab masih manual dan tidak terekam dengan rapih untuk penilaian. Dengan adanya sistem ini akan memudahkan Asisten Lab dan Penanggung Jawab dalam Absensi hadir dan ada rekapan yang jelas untuk Penilaian Akhir.

\section{METODE PENELITIAN}

Terdapat 6 tahapan yang diterapkan dalam penyusunan penelitian ini yaitu: Perumusan Masalah, Perancangan Penelitian, Pengumpulan Data, Pengelolahan Data, Analisis Data Penelitian dan Laporan Penelitian.

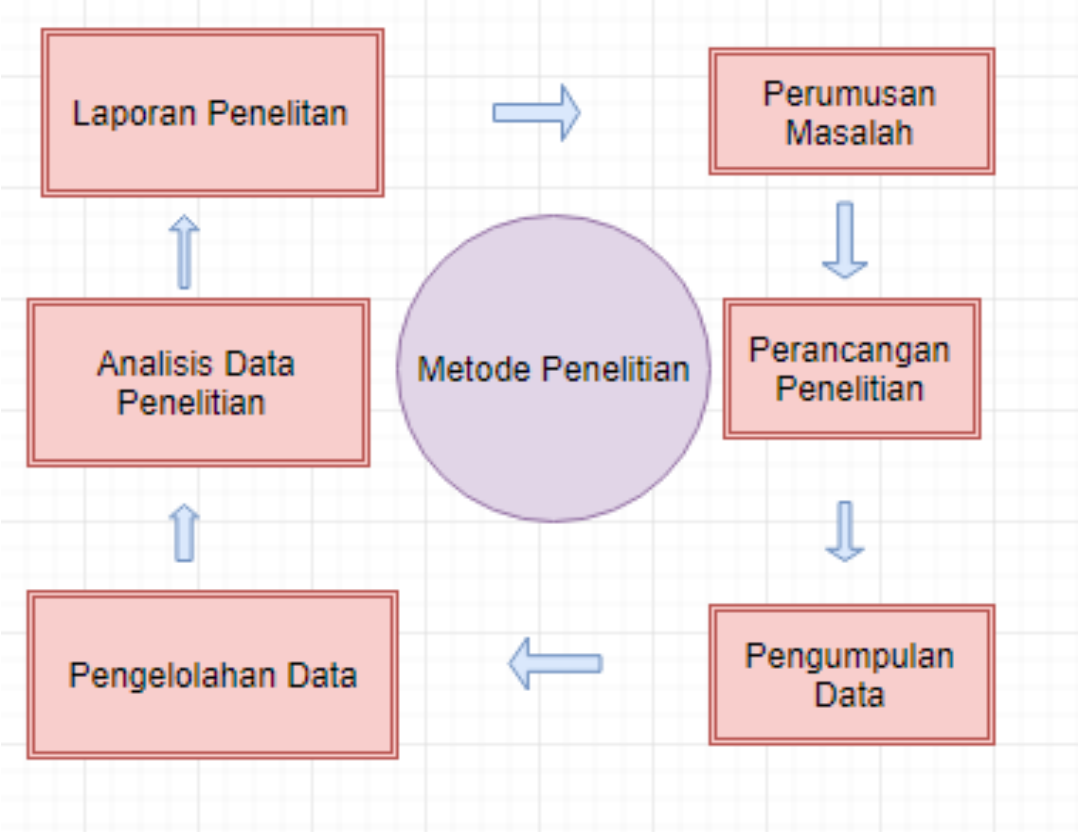

Gambar 2. Metode Penelitian

Keterangan :

a. Perumusan Masalah, Yaitu melakukan observasi secara lebih dalam agar mengetahui letak permasalahan alur yang sedang berjalan.

b. Perancangan Penelitian, Yaitu setelah melakukan observasi masalah dan sudah mengetahui masalahannya lalu selanjutnya membuat Prototype pada blueprint.

c. Pengumpulan Data, Yaitu dalam membuat sebuah sistem baiknya kita mengumpulkan data.

d. Pengolahaan Data, Yaitu ketika sudah mengumpulkan data langkah selanjutnya adalah mengolah data yang rapi.

e. Analisis Data Penelitian, Yaitu dalam mengumpulkan data mengolah data dan langkah selanjutnya adalah analisa data

f. Laporan Penelitian, Yaitu laporan untuk penelitian dan siap implementasi 


\section{HASIL DAN PEMBAHASAN}

\subsection{Analisa Permasalahan}

Absensi Kegiatan Tri dharma di Perguruan Tinggi Raharja saat ini masih menggunakan sistem yang manual diawali dengan asisten lab menginput NIM dan password di RME dengan proses absensi tersebut sering terjadi manipulasi. Kemudian penanggung jawab asisten lab merekap absensi asisten lab dengan menginput NIM atau password secara satu persatu di RME.

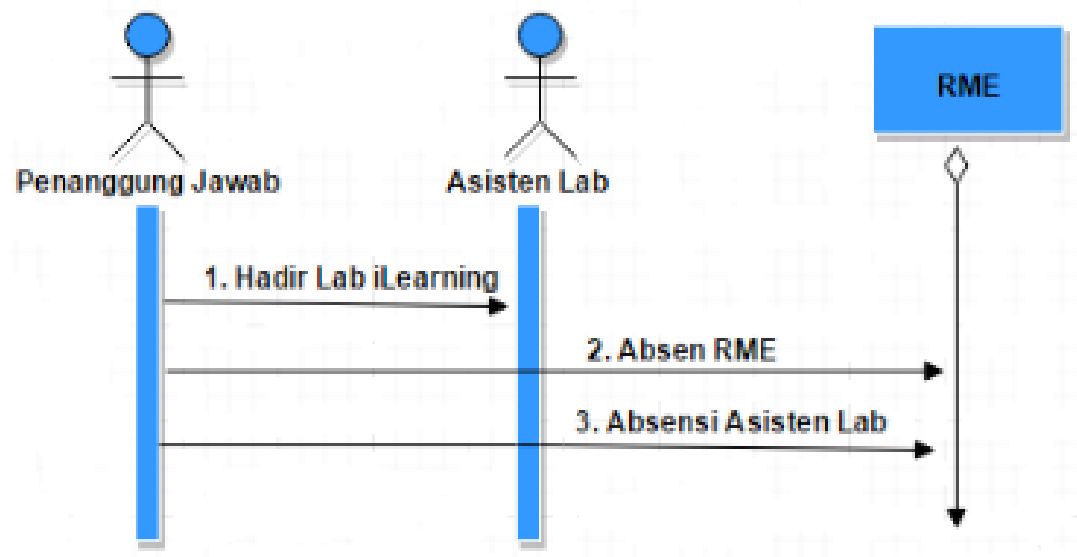

Gambar 3. Sequence Diagram

Gambar diatas merupakan tampilan alur absensi yaitu penanggung jawab asisten lab hadir di lab ilearning lalu absen RME kemudian asisten lab hadir dan absen RME.

\subsection{Pemecahan Permasalahan}

Dari permasalahan di atas penulis menciptakan sistem baru yaitu Pensil (Penilaian Asisten Lab) untuk proses absensi asisten lab menggunakan Qrcode sebagai media absensi yang memberikan pelayanan yang canggih dan efektif untuk membantu penanggung jawab asisten lab merekap absensi dengan baik.
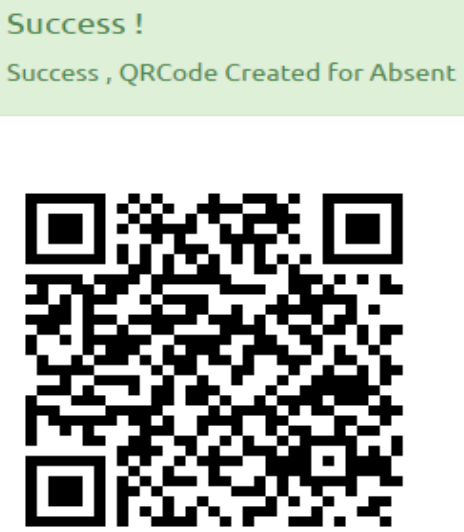

(c) Pensil 2017

Gambar 4. Penerapan Qrcode pada sistem Pensil 
$Q R$ Code adalah sebuah kode batang dua dimensi yang ditemukan oleh sebuah perusahaan Jepang bernama Denso Wave pada tahun 1994. QR Code ini adalah pengembangan dari kode batang sebelumnya. Pada model barcode lama, data disimpan secara horizontal saja sedangkan pada QR Code, data disimpan baik secara vertikal maupun horizontal.

\subsection{Listing Program}

Qrcode dapat dimanfaatkan sebagai keamanan makanan dengan cara menambahkan kode QR yang berisikan data-data mengenai kandungan nutrisi dan masa kedaluwarsa pada tiap label makanan sehingga pelanggan dapat merasa lebih aman dalam memilih makanan yang dibeli sebab mereka dapat mengetahui informasi-informasi tentang makanan tersebut. Di Jepang, hal ini telah diterapkan oleh McDonald. Terdapat 19 jenis "sandwich" yang diberi kode QR yang mengandung informasi alergi, jumlah kalori dan nutrisi yang terkandung dalam sandwich tersebut. Selain itu kode QR juga dapat diberikan di halte bus, sehingga penumpang dapat mengetahui keberadaan bus yang sedang ditunggu. Cara kerjanya adalah dengan memberikan hipertaut ke kamera CCTV di setiap jalan melalui koneksi internet pada ponsel. Lebih lanjut lagi, kode QR dapat dipasang pada kartu pelajar, sehingga akan mempermudah proses absensi siswa, dan mempermudah akses bagi para siswa,guru, dan orang tua murid kepada informasi proses belajar mengajar.

Berikut listing program dalam menyusun sistem ini :

1. Menampilkan Menu Generate qrcode

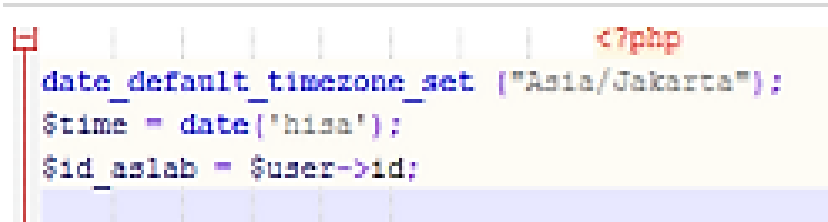

Gambar 5. Konfigurasi untuk membuat qrcode

2. Qrcode di enkripsi dengan md5

Md5 adalah MD5 (Message-Digest algortihm 5) ialah fungsi hash kriptografik yang digunakan secara luas dengan hash value 128-bit. Pada standart Internet (RFC 1321), MD5 telah dimanfaatkan secara bermacam-macam pada aplikasi keamanan, dan MD5 juga umum digunakan untuk melakukan pengujian integritas sebuah berkas.

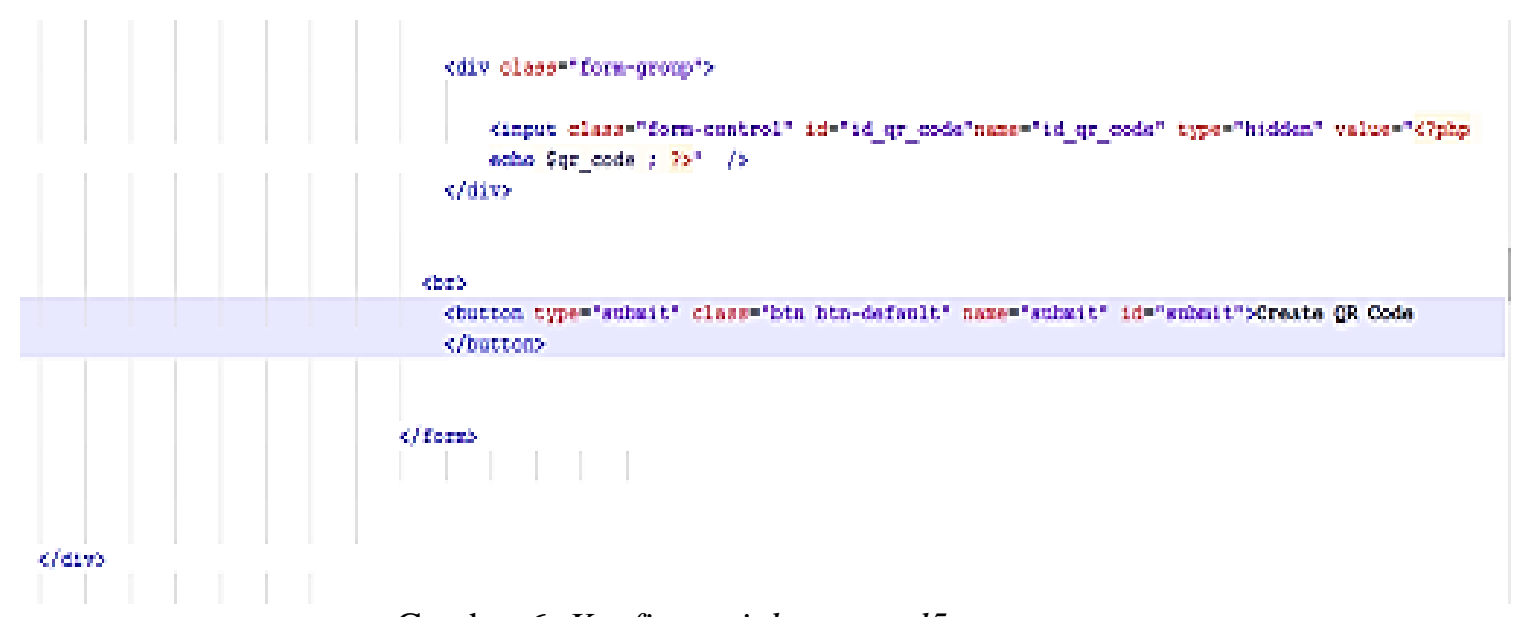

Gambar 6. Konfigurasi dengan md5 
3. Setelah membuat Form HTML, selanjutnya kita membuat kode PHP \$_GET untuk menerima informasi yang telah dikirim oleh Form.

Metode Get Php adalah metode pengiriman data menggunakan query string, jadi seluruh nilai pada form akan di kirim ke sisi server/file dan nilai dari form akan tampil pada barus URL/ Address bar Pada Metode GET, Variabel terlihat pada URL, data setiap variabel dipisahkan dengan \&. Contoh http://url/page.php?get1=nilai2\&get2=nilai2

Dibatasi oleh panjang string sebanyak 2047 karakter Memungkinkan pengunjung langsung memasukkan nilai variable pada form proses. Lalu setelah itu upload di fillezilla script yang tadi kita koding di notepad++ dan menampilkan Menu Generate Qrcode.

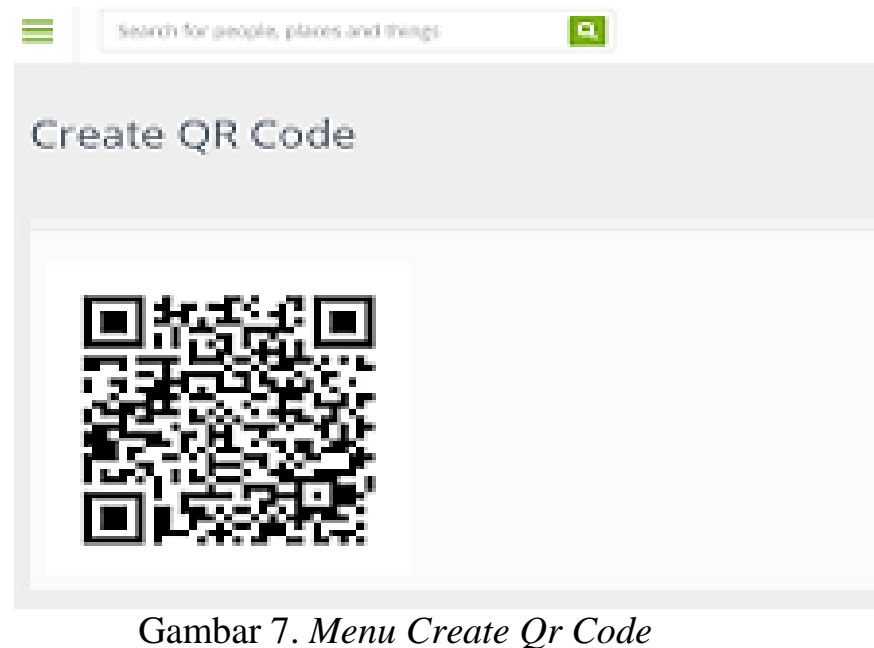

Gambar 7. Menu Create Qr Code

4. Menampilkan form create qrcode

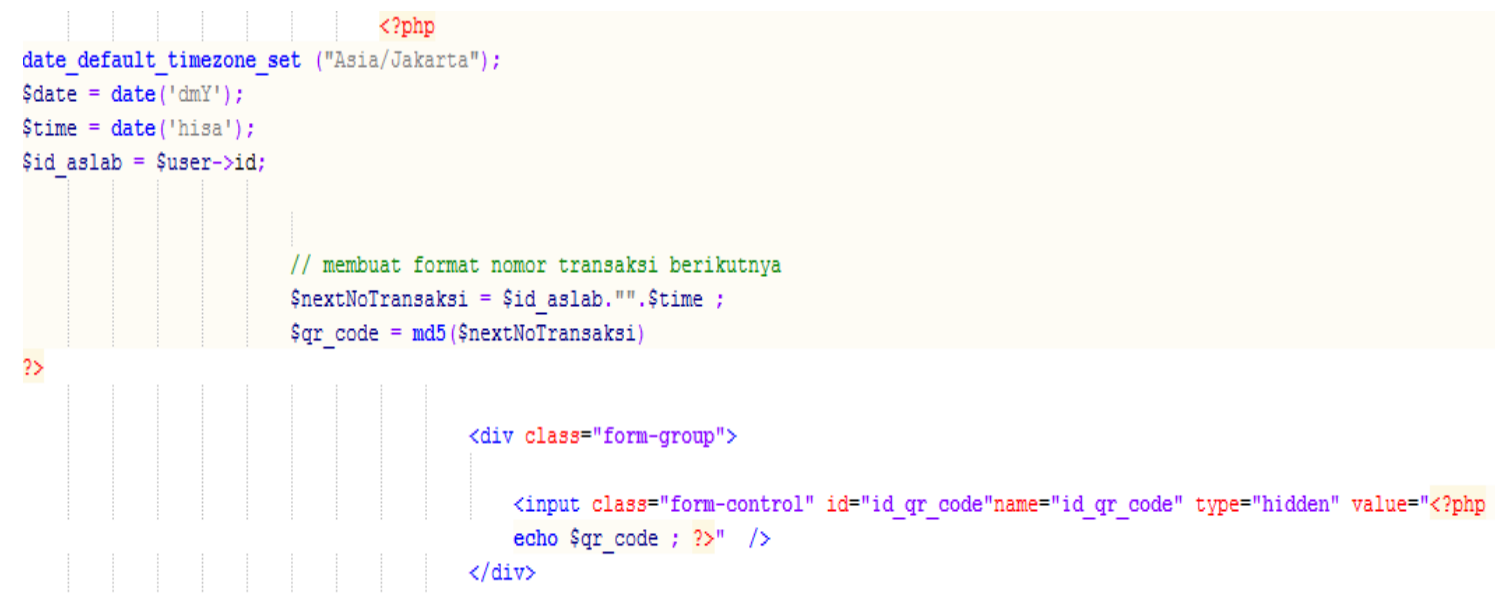

Gambar 8. Konfigurasi create qrcode

5. menampilkan hasil generate qrcode dari form tersebut 


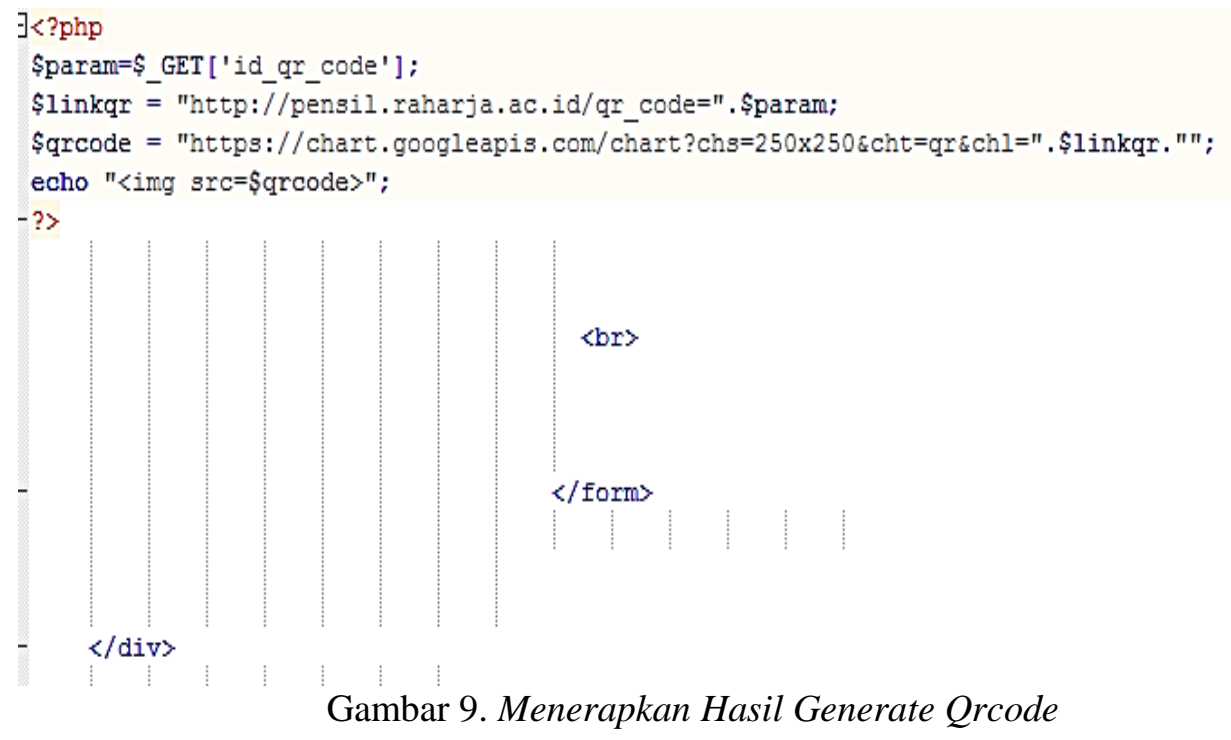

6. Hasil dari menampilkan Generate Qrcode

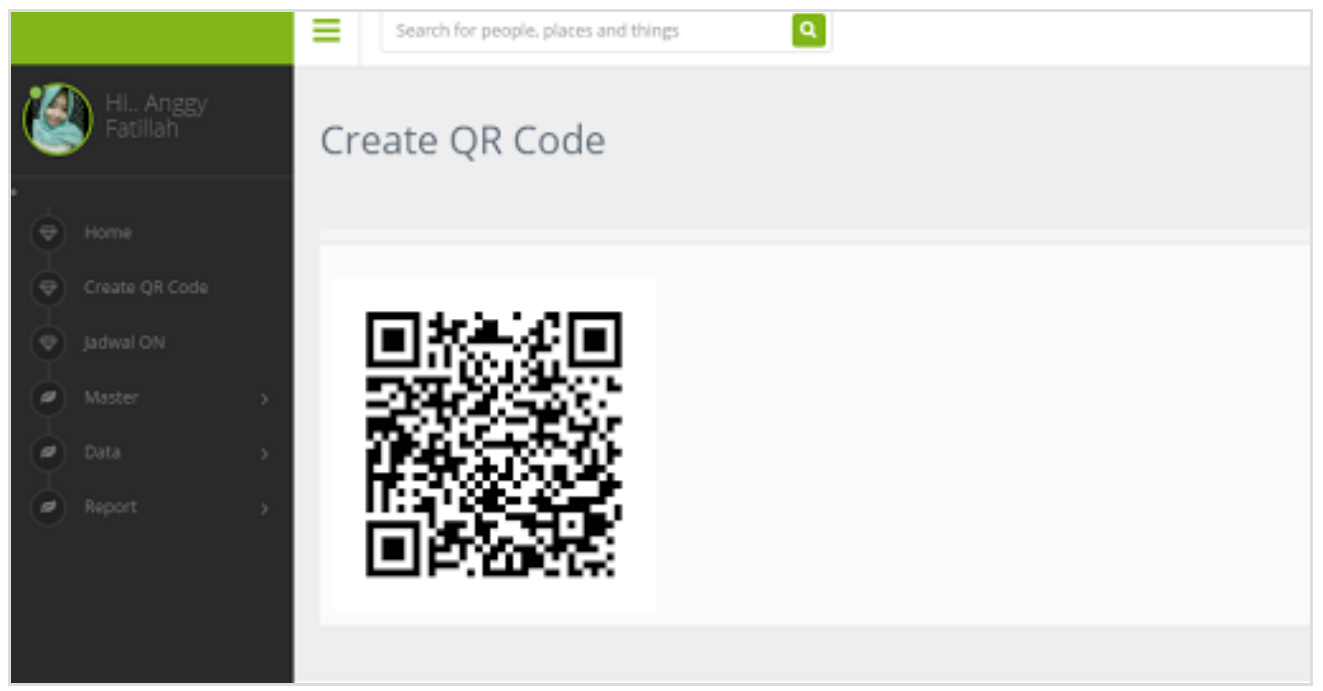

Gambar 7. Menampilkan Qrcode

\subsection{Implementasi}

Perancangan sistem yang dibuat dengan hasil analisa akhirnya dapat terealisasikan dengan adanya sistem Pensil (Penilaian Asisten Lab) proses absen asisten lab menjadi sangat efektif dan sangat mudah dengan scan Qrcode asisten lab sudah bisa absen sehingga tidak terjadi manipulasi absen. 


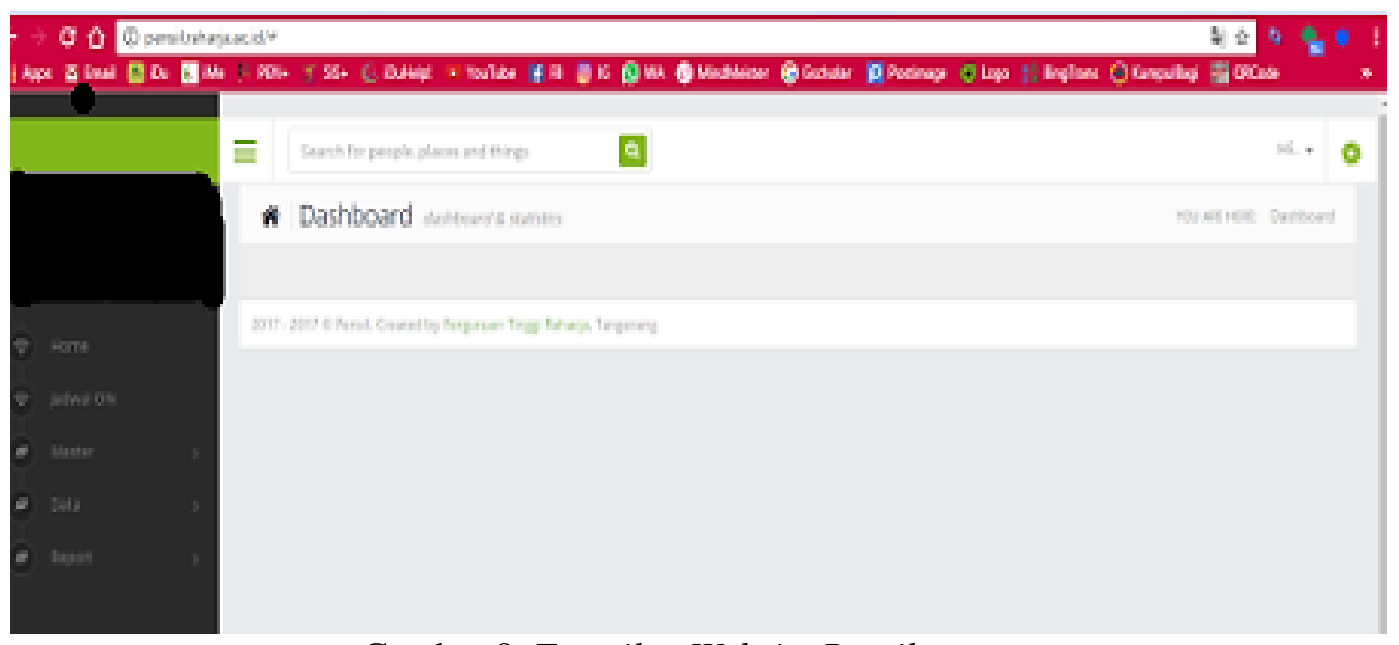

Gambar 8. Tampilan Website Pensil

Adanya sistem ini sangat membantu penanggung jawab asisten lab untuk memberikan penilaian dan merekap absensi asisten lab yang menjalankan Tri dharma di Perguruan Tinggi Raharja.

\section{KESIMPULAN}

Berdasarkan penelitian di atas dapat disimpulkan bahwa absensi dengan scan Qrcode mempermudah penanggung jawab asisten lab untuk memberikan penilaian absensi terhadap kegiatan Tri dharma asisten lab dan mempermudah asisten lab untuk absensi dengan proses absensi scan Qrcode ini sehingga tidak terjadinya manipulasi absen lagi.

\section{SARAN}

Berdasarkan dari penjelasan yang telah penulis sampaikan diatas, maka penulis dapat menyimpulkan saran dari penjelasan tersebut, antara lain:

a. Harus menggunakan pemindai untuk mengetahui isi dari QR Code tersebut.

b. Kualitas pemindaian bergantung pada ketajaman alat pemindai.

c. QR Code sangat sulit terbaca apabila ukuran mengalami penyusutan.

\section{UCAPAN TERIMA KASIH}

Penulis mengucapkan terima kasih kepada Perguruan Tinggi Raharja yang telah memberikan fasilitas dan memberikan dukungan terhadap penelitian ini.

\section{DAFTAR PUSTAKA}

[1] Imron, Ali. 1994 Manajemen peserta didik, jilid I / Ali Imron. Malang : Proyek OPF IKIP Malang

[2] Aini, Q., Graha, Y.I. and Zuliana, S.R., 2017. Penerapan Absensi QRCode Mahasiswa Bimbingan Belajar pada Website berbasis YII Framework. SISFOTENIKA, 7(2), pp.207-218.

[3] Erna Simonna.2009. Definisi Absensi: (http://simonna-erna.blogspot.com) [Accessed 20 September 2017]. 
[4] Anwar Khoirul.(2015). Peningkatan Aktivitas dan Hasil Belajar Siswa dalam Turunan Fungsi Melalui Model Pembelajaran Jigsaw Berbantuan Student Activities Handout. Jurnal Kreano.

[5] Rahardja, U., Sholeh, O. and Nursetianingsih, F., 2015. Penggunaan Dashboard untuk Mengontrol Kinerja Absensi Pegawai Guna Meningkatkan Profesionalisme Pegawai pada PT. Sinarmas Land property. SEMNASTEKNOMEDIA ONLINE, 3(1).

[6] Sunarya, A., Rahardja, U. and Wanda, A., Kepuasan Pelanggan Rooster Atas Kinerja Pelayanan Rooster pada Perguruan Tinggi Raharja.

[7] Rohman.Abdul.2008. Analisa Sistem Informasi Absensi Pegawai DPRD Kota Tangerang,KKP Raharja:Tangerang

[8] Rukmiati, Dhita. 2009. Pengembangan Sistem Informasi Pegawai Pada Perguruan Tinggi Raharja. Tangerang. SKRIPSI STMIK Raharja. 